\title{
Refractory period following induced asthma: contributions of exercise and isocapnic hyperventilation
}

\author{
ISSASCHAR BEN-DOV, ILAN GUR, EPHRAIM BAR-YISHAY, SIMON GODFREY \\ From the Pulmonary Function Laboratory and Department of Pediatrics, Hadassah University Hospital at \\ Mount Scopus, Jerusalem, Israel
}

ABSTRACT To compare the refractory period that follows exercise and isocapnic hyperventilation, 10 asthmatic children performed two pairs of challenge tests in random order at least six hours apart. In pair A a hyperventilation challenge was followed by an exercise challenge and in pair B the order was reversed. Both pairs of tests were done while the children were breathing cold dry air. Tests were matched in terms of work load, ventilation, and end tidal carbon dioxide tension $\left(\mathrm{PCO}_{2}\right)$. The mean percentage fall in $\mathrm{FEV}_{1}\left(\Delta \mathrm{FEV}_{1}\right)$ after the first challenge (hyperventilation) of pair $A$ and the first challenge (exercise) of pair B were the same (30\% (SEM 2\%)) and 30\% (4\%) respectively). The mean $\Delta \mathrm{FEV}$, of the exercise test following hyperventilation in pair $\mathrm{A}$ and of hyperventilation following exercise in pair B was $22 \%(4 \%)$ and $18 \%(4 \%)$ respectively. Both these latter results were significantly lower than the respective $\Delta \mathrm{FEV}_{1}$ when the challenge was the first test of the pair. Although the mean refractoriness index (reduction in induced asthma in the second test of each pair compared with the first test) was greater when exercise was the first challenge, the difference was not significant.

The existence of a refractory period after exercise induced asthma is a well established phenomenon. ${ }^{1-3}$ Isocapnic hyperventilation can also induce asthma attacks ${ }^{4-6}$ and it has been found that this hyperventilation induced athma is likewise able to render subjects refractory to a subsequent challenge by hyperventilation. ${ }^{78}$ Exercise and hyperventilation differ from each other when their capability to induce refractoriness during the breathing of warm humid air is compared. We and others ${ }^{910}$ showed that asthmatic patients developed refractoriness to a subsequent exercise test when warm humid was breathed during the first test even though this first test with warm humid air did not itself result in exercise induced asthma. In contrast, we did not find that hyperventilation of warm humid air induced refractoriness to subsequent hyperventilation induced asthma. ${ }^{8}$ To explain these observations we proposed a model in which exercise and hyperventilation act in different lung zones. ${ }^{9}$ The effect of cooling during

Address for reprint requests: Professor S Godfrey, Department of Pediatrics, Hadassah University Hospital at Mount Scopus, Jerusalem, Israel.

Accepted 11 July 1983 hyperventilation might be mainly on the central airways, while exercising might mainly affect the peripheral lung zones. At each site we believed the trigger mechanisms caused degranulation of mast cells with mediator release. Refractoriness would then be due to exhaustion of mediator stores at the trigger site.

If indeed exercise and hyperventilation have different trigger sites, their ability to produce refractoriness against each other might differ from their ability to induce refractoriness against the same stimulus. This paper presents the results of studies of the effect of exercise induced asthma on hyperventilation induced asthma and vice versa.

\section{Methods}

Ten asthmatic children and adolescents participated in the study (table 1). They and their parents gave consent to repeated bronchial provocation after a full explanation of the procedure. Patients refrained from taking sympathomimetic medications for at least eight hours, sodium cromoglycate for 12 hours, and long acting theophyllines for 24 hours before 
Table 1 Data on the asthmatic patients studied

\begin{tabular}{lllll}
\hline Subject & $\begin{array}{l}\text { Age } \\
(y)\end{array}$ & $\begin{array}{l}\text { Weight } \\
(\mathrm{kg})\end{array}$ & $\begin{array}{l}\text { Height } \\
(\mathrm{cm})\end{array}$ & $\begin{array}{l}\text { Regular } \\
\text { treatment }\end{array}$ \\
\hline 1 & 11 & 34 & 140 & ISB \\
2 & 14 & 41 & 147 & ISB \\
3 & 12 & 30 & 145 & HDT, ISB \\
4 & 11 & 40 & 145 & ISB \\
5 & 12 & 35 & 139 & BDP, ISB \\
6 & 12 & 30 & 142 & ISB \\
7 & 12 & 29 & 139 & ISB \\
8 & 14 & 35 & 145 & SCG, ISB \\
9 & 15 & 38 & 158 & SCG, ISB \\
10 & 16 & 48 & 163 & BDP, ISB \\
\hline
\end{tabular}

*ISB-Intermittent sympathomimetic bronchodilators; SCG-sodium cromoglycate; HDT-high dose theophylline: BDP-beclomethasone dipropionate.

any test. Inhaled steroid treatment was continued at the same level throughout all tests.

The study consisted of isocapnic hyperventilation followed by an exercise test (test pair A) and an exercise test followed by isocapnic hyperventilation (test pair B). All tests were performed while the subjects breathed cold dry air (mean temperature $7 \cdot 8^{\circ} \mathrm{C}\left(\mathrm{SEM} 1.4^{\circ} \mathrm{C}\right)$ and humidity $3.4(0.4) \mathrm{mg} \mathrm{H}_{2} \mathrm{O} /$ 1). The test gas was produced by passing air through a calcium chloride drying chamber and then through a refrigeration coil. It was supplied to the subject through an insulated respiratory circuit containing a reservoir bag and a one way valve box. The two pairs of tests were performed in a random order on the same day with an interval of at least six hours between the pairs. Each test lasted six minutes. The interval between the two tests of each pair was 30-50 minutes and was kept constant for each participant. The children were encouraged to exercise at a work load calculated to achieve about $60 \%$ of their maximum predicted oxygen consumption. For those who performed the hyperventilation challenge test first the level of ventilation set was that which would be developed during exercise at $60 \%$ of their maximum predicted oxygen consumption. These calculations were made with the data of Godfrey. ${ }^{\text {" }}$ The desired ventilation was achieved by means of an electronic device indicating target ventilation. During the hyperventilation tests end tidal $\mathrm{PCO}_{2}$ was kept at resting level by adding $1-2 \%$ carbon dioxide $\vec{F}$ to the inspired air.

Inspired and expired air temperature, ventilation, and end tidal $\mathrm{PCO}_{2}$ were monitored and automatically recorded every half minute (PK Morgan Exercise Testing System, England). Lung function was measured with a Hewlett Packard 47804A pulmo- क nary calculator system (Hewlett Packard Co, $\vec{\circ}$ California), so connected that the subject continued to inhale cold dry air throughout the whole test period and during lung function measurements. Lung function measurements were obtained before and at intervals after the test, until the FEV, had returned to within $\pm 10 \%$ of the pre-test value. The subject then started the second challenge of each pair.

Results are expressed as percentage maximal post-test fall in $\mathrm{FEV}_{1}\left(\Delta \mathrm{FEV}_{1}\right)$, defined as

$\Delta \mathrm{FEV}_{1}=\frac{\text { pre-test } \mathrm{FEV}_{1}-\text { lowest post-test } \mathrm{FEV}_{1}}{\text { pre-test } \mathrm{FEV}_{1}} \times 100$ where pre-test values were those measured brea- $\frac{0}{0}$ thing cold dry air just before starting the challenge. $\stackrel{\mathbb{D}}{-}$ In addition, an index of refractoriness, $\mathrm{RI}(\%)$, was $\vec{\bullet}$ calculated for each pair by comparing the $\Delta F E V_{1}$ in the first and second tests of each pair as follows:

$\mathrm{RI}(\%)=\frac{1 \text { st test } \Delta \mathrm{FEV} V_{1}-2 \text { nd test } \Delta \mathrm{FEV}_{1}}{1 \text { st test } \Delta \mathrm{FEV}} \times 100$

Respiratory heat loss was calculated with the equation of Deal et al. ${ }^{12}$

Statistical comparisons were made by means of $\overrightarrow{\vec{P}}$ paired $t$ tests and non-parametric tests as appropriate.

\section{Results}

Minute ventilation and respiratory heat loss for the four challenges are shown in table 2. The only significant difference was a $9.5 \%$ lower respiratory heat loss during hyperventilation tests $(p=0.04) \delta$ than during exercise. There was no significant difference in respiratory heat loss between the two 을 hyperventilation tests or between the two exercise tests. The heart rates during the exercise tests were

Table 2 Mean (SEM) values of challenge FEV, before challenge ventilation, and heat exchange for the four tests

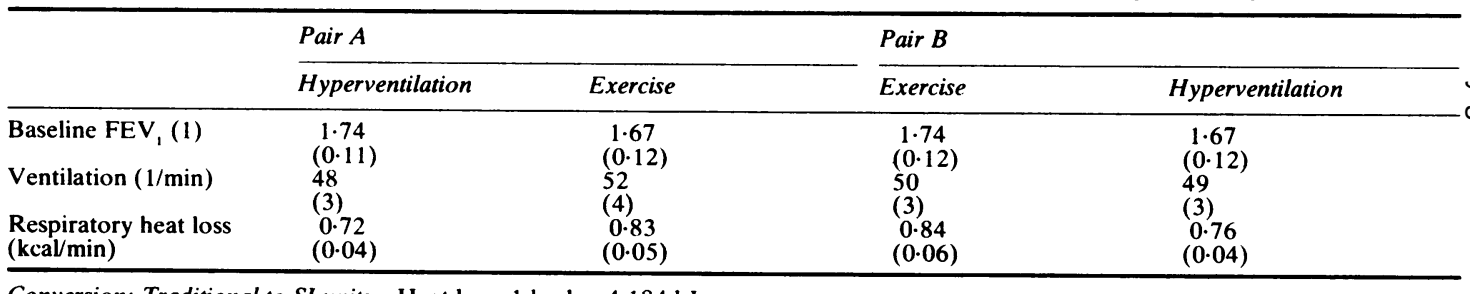

Conversion: Traditional to SI units-Heat loss: $1 \mathrm{kcal}=4 \cdot 184 \mathrm{~kJ}$. 
Table 3 Individual values of baseline $F E V_{1}(1)$ and maximum fall in $F E V_{1}$ after challenge $\left(\triangle F E V_{1}\right)(\%)$ for each of the four challenge tests

\begin{tabular}{|c|c|c|c|c|c|c|c|c|}
\hline \multirow[t]{3}{*}{ Subject } & \multicolumn{4}{|l|}{ Pair $A$} & \multicolumn{4}{|l|}{ Pair B } \\
\hline & \multicolumn{2}{|c|}{ Hyperventilation } & \multicolumn{2}{|c|}{ Exercise } & \multicolumn{2}{|c|}{ Exercise } & \multicolumn{2}{|c|}{ Hyperventilation } \\
\hline & $\begin{array}{l}\text { Basal } \\
F E V_{1}\end{array}$ & $\begin{array}{l}\Delta \\
F E V_{1}\end{array}$ & $\begin{array}{l}\text { Basal } \\
\text { FEV }\end{array}$ & $\stackrel{\Delta}{F E V_{1}}$ & $\begin{array}{l}\text { Basal } \\
\text { FEV }\end{array}$ & $\stackrel{\Delta}{F E V_{1}}$ & $\begin{array}{l}\text { Basal } \\
\text { FEV }\end{array}$ & $\stackrel{\Delta}{\boldsymbol{F} E V_{1}}$ \\
\hline $\begin{array}{c}1 \\
2 \\
3 \\
4 \\
5 \\
6 \\
7 \\
8 \\
9 \\
10 \\
\text { Mean } \\
\text { SEM }\end{array}$ & $\begin{array}{l}1.51 \\
2.08 \\
1.83 \\
1.65 \\
1.50 \\
1.84 \\
1.34 \\
2.07 \\
1.24 \\
2.32 \\
1.74 \\
0.11\end{array}$ & $\begin{array}{r}32 \\
34 \\
29 \\
36 \\
33 \\
18 \\
20 \\
36 \\
31 \\
32 \\
30 \\
2\end{array}$ & $\begin{array}{l}1.33 \\
1.94 \\
1.75 \\
1.62 \\
1.48 \\
1.77 \\
1.30 \\
1.95 \\
1.16 \\
2.32 \\
1.66 \\
0.11\end{array}$ & $\begin{array}{l}44 \\
22 \\
41 \\
13 \\
22 \\
13 \\
19 \\
10 \\
12 \\
22 \\
22 \\
4\end{array}$ & $\begin{array}{l}1.49 \\
2.14 \\
1.89 \\
1.66 \\
1.47 \\
1.84 \\
1.37 \\
2.07 \\
1.12 \\
2.38 \\
1.74 \\
0.12\end{array}$ & $\begin{array}{r}52 \\
40 \\
35 \\
14 \\
22 \\
11 \\
40 \\
19 \\
41 \\
22 \\
30 \\
4\end{array}$ & $\begin{array}{l}1.33 \\
2.13 \\
1.84 \\
1.51 \\
1.50 \\
1.80 \\
1.33 \\
1.90 \\
1.07 \\
2.33 \\
1.67 \\
0.12\end{array}$ & $\begin{array}{r}42 \\
24 \\
15 \\
15 \\
9 \\
2 \\
31 \\
14 \\
21 \\
10 \\
18 \\
4\end{array}$ \\
\hline
\end{tabular}

very similar (171 (3) beats/min when exercise was the first test of the pair and $179(6)$ beats/min when it was the second test of the pair). There was also no significant difference in end tidal $\mathrm{PCO}_{2}$ between the two hyperventilation tests.

The baseline $\mathrm{FEV}_{1}$ values and the maximum fall after challenge for each subject are given in table 3 , and summarised in the figure. The mean baseline FEV , before the second challenge of each pair was $4 \%$ lower than before the first $(\mathrm{p}=0.02)$. When we compared the results of two hyperventilation tests, the first challenge of test pair $A$ resulted in a significantly greater $\triangle F V_{1}$ than the second challenge of test pair $B\left(\triangle F E V_{,}=30 \%(2 \%)\right.$ and $18 \%$ $(4 \%)$ respectively; $p=0.008)$-that is to say, the exercise test which preceded hyperventilation in test pair $B$ rendered the patients relatively refrac-

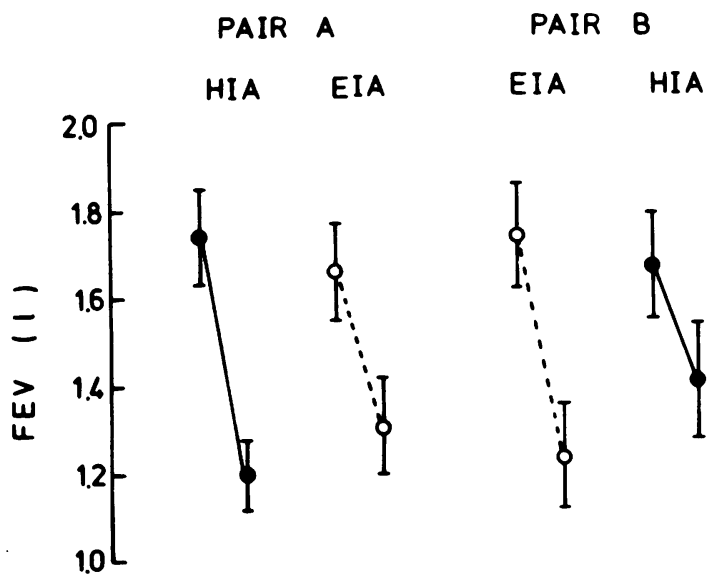

Fig 1 Means and SEM of FEV, before challenge and the lowest values after challenge for the two pairs of tests. EIA -xercise induced asthma: HIA-hyperventilation induced asthma. tory to the hyperventilation challenge. When the results of the two exercise tests are compared, the first challenge of pair B resulted in a significantly greater $\triangle F E V_{1}$ than the second challenge of test pair $\mathrm{A}(\Delta \mathrm{FEV}, 30 \%(2 \%)$ and $22 \%(4 \%)$ respectively; $p=0.03$ ). Thus the hyperventilation which preceded the exercise in test pair $A$ also induced a degree of refractoriness to exercise. If we compare the first test of each pair (hyperventilation first in pair $A$ and exercise first in pair B),there was no significant difference in their $\Delta \mathrm{FEV}_{1}(30 \%(4 \%)$ and $30 \%(2 \%)$ respectively). Similarly, the second test of each pair (exercise after hyperventilation in pair $A$ and hyperventilation after exercise in pair B) produced very similar values for $\triangle F E V_{1}(22 \%$ $(4 \%)$ and $18 \%(4 \%)$ respectively; $p=0.18)$.

That the small but significant reduction $(4 \%)$ in resting $F E V_{1}$ before the second challenge of each pair did not account for the lower $\triangle F E V_{1}$ can be seen from the figure, as the absolute $\mathrm{FEV}_{1}$ after the challenge of the second test was higher than that after the first test-that is, the $F E V_{1}$ could have fallen lower after the second test had the stimulus required it. The difference between the absolute $\mathrm{FEV}_{1}$ values after the challenges of the first and second tests of each pair was significant when exercise was the first test $(p<0.01)$ but not when hyperventilation was the first test, which suggests that exercise was a more effective inducer of refractoriness.

The mean refractoriness index when hyperventilation was the first test of the pair was $25 \%(12 \%)$ and when exercise was the first test of the pair it was $40 \%(8 \%)$. This difference, however, was not significant according to a paired $t$ test or the Wilcoxon non-parametric ranking method. The refractoriness index after hyperventilation was very variable and ranged from $72 \%$ (good protection) to $-41 \%$ (more asthma in the second test than in the first). 


\section{Discussion}

This study has indicated that exercise induced asthma can make a subject refractory to hyperventilation induced asthma and vice versa. The refractoriness in the present study was less than what we found after repetition of the same stimulus. Thus when the two challenges in the pair of tests were both exercise ${ }^{9}$ the mean refractoriness index was $60 \%(6 \%)$ and when they were both hyperventilation $^{8}$ it was $44 \%(15 \%)$. In both these previous studies the subjects breathed cold dry air and their respiratory heat loss was very similar to that in the present study. The absolute values must reflect individual variability in sensitivity to whatever provokes the asthma, but it is interesting that the ratio of the refractoriness index for exercise to the refractoriness index for hyperventilation from these two previous studies $(1: 4)$ is similar to the ratio from the present study when the value for test pair $B$ is divided by that for test pair $A(1: 6)$. A similar difference in the efficacy of the induction of refractoriness by exercise and hyperventilation is found by calculating the mean refractoriness index from the study of Edmunds et $a^{3}$ for an interval of 40 minutes between exercise tests (about $50 \%$ ) and from the study of Wilson $e t \mathrm{al}^{7}$ when the refractoriness index for hyperventilation was $33 \%$; but the conditions of these two studies were not identical to those of the present study.

The similarity in the magnitude of response to the first test of each pair whether it was exercise or hyperventilation favours the respiratory heat loss hypothesis, ${ }^{4-6}$ in which exercise induced asthma is simply a result of airway cooling associated with hyperventilation and is thus just a manifestation of hyperventilation induced asthma. In the present study, however, and in both of our previous studies $^{89}$ we found that our subjects developed similar amounts of asthma after the exercise and hyperventilation challenges, even though the RHL was $14 \%$ lower during the hyperventilation studies. There was a tendency, albeit not statistically significant, for hyperventilation to be a weaker inducer of refractoriness than exercise as judged by the refractoriness index. We must consider the possibility that the difference is due simply to the fact that the RHL was lower in the hyperventilation tests. If we accept, however, that refractoriness is due to the depletion of whatever mediators provoke the asthma (see below) then, as in both the present and previous studies the severity of exercise induced and hyperventilation induced asthma in the first test of the pair was virtually identical, the two forms would be expected to induce equal amounts of refractoriness.
Stearns et al $^{14}$ proposed that the refractory period after exercise induced asthma was probably due to $\stackrel{\oplus}{+}$ factors such as increased sympathomimetic drive, because Deal et al ${ }^{15}$ did not find mediator release (histamine or neutrophil chemotactic factor) in hyperventilation induced asthma and because they did not find a refractory period after it. In these in studies they assumed that exercise induced asthma was equivalent to hyperventilation induced asthma. Other studies have, however, shown refractoriness after the latter. ${ }^{78}$ If anything, there is a reduced catecholamine drive in asthmatics during exercise $\vec{x}$ and no detectable adrenergic response during hyperventilation induced asthma. ${ }^{16}$ In a recent study by Lee et al $^{17}$ it was shown that neutrophil chemotactic factor is liberated during exercise induced asthma and that its liberation and the asthma can both be prevented by pretreatment with sodium cromoglycate. The weight of evidence thus favours mediator $z$ release in exercise induced asthma at least: possibly mediator is also released in hyperventilation induced asthma but in quantities too small to be detected in the blood.

Perhaps exercise and hyperventilation result in $\vec{\bullet}$ refractoriness to each other because they both liberate mediator and when this binds to the bronchial smooth muscle the muscle itself becomes refractory to further stimulation. There is no evidence to support this idea at present and refractoriness is not found with repeated histamine challenges. ${ }^{18} 19$

Can the present studies shed any additional light on the controversy about whether exercise induced asthma is simply hyperventilation induced asthma and results from loss of heat from the airways? We have previously shown that subjects become refractory to a subsequent exercise challenge even when the initial exercise test is carried out when they are breathing warm humid air and does not itself result $x$ in exercise induced asthma. ${ }^{9}$ This phenomenon does not occur when both challenges are hyperventilation. ${ }^{8}$ We thought that this was due to the local 0 release of mediators owing to the cooling of large airways during hyperventilation while with exercise the mediator release was from deep within the lung $\rightarrow$ and independent of temperature except in a permissive role. If this were so we should not expect hyper- $N$ ventilation induced asthma to render subjects refractory to exercise induced asthma-although, $\mathcal{N}$ since exercise leads to hyperventilation, we should $\omega$ expect exercise induced asthma to make them? refractory to hyperventilation induced asthma. Ouro finding that the latter did induce refractoriness to $\mathbb{D}$ exercise induced asthma is not compatible with this ${ }^{+}$ hypothesis. Possibly, however, hyperventilation 0 releases mediators locally in large airways as a result of cooling and these mediators, either directly or 
reflexly, result in further discharge of mediators from mast cells deep in the lung and hence hyperventilation induced asthma results in refractoriness to exercise induced asthma.

Although we have been unable to show a significant difference between the indices of refractoriness associated with hyperventilation induced asthma and with exercise induced asthma, the measurements of absolute $\mathrm{FEV}_{1}$ after challenge suggest that hyperventilation induced asthma may be a poorer inducer of refractoriness. Other studies 38913 also suggest that it is the weaker inducer of refractoriness and we believe that, taken as a whole, the available evidence is compatible with our contention that exercise induced and hyperventilation induced asthma are not one and the same thing.

\section{References}

' McNeill RS, Nairn JR, Miller JS, Ingram CG. Exercise induced asthma. $Q J$ Med 1966;35:55-67.

${ }^{2}$ Chan-Yeung MMW, Vyas MN, Grzybowski S. Exercise-induced asthma. Am Rev Respir Dis 1971;104:915-23.

${ }^{3}$ Edmunds T, Tooley M, Godfrey S. The refractory period after exercise-induced asthma: its duration and relation to the severity of exercise. Am Rev Respir Dis 1978;117:247-54.

${ }^{4}$ Deal EC, McFadden ER, Ingram RH, Jaeger JJ. Hyperpnea and heat flux: initial reaction sequence in exercise-induced asthma.J Appl Physiol: Respir Environ Exercise Physiol 1979;46:476-83.

${ }^{5}$ Chen WY, Weiser PC, Chai H. Airway cooling stimulus for exercise-induced asthma. Scand J Respir Dis 1979;60:144-50.

- Kilham H, Tooley M, Silverman M. Running, walking and hyperventilation causing asthma in children. Thorax 1979;34:582-6.
${ }^{7}$ Wilson NM, Barnes PJ, Vickers H, Silverman M. Hyperventilation-induced asthma: evidence for two mechanisms. Thorax 1982;37:657-62.

${ }^{8}$ Bar-Yishay E, Ben-Dov I, Godfrey S. Refractory period following hyperventilation-induced asthma. Am Rev Respir Dis 1983;127:572-4.

${ }^{9}$ Ben-Dov I, Bar-Yishay E, Godfrey S. Refractory period following exercise-induced asthma unexplained by respiratory heat loss. Am Rev Respir Dis 1982;125:530-4.

${ }^{10}$ Henriksen JM, Dahl R, Londquist GR. Influence of relative humidity and repeated exercise on exerciseinduced bronchoconstriction. Allergy 1981;36:46370.

$"$ Godfrey S. Exercise testing in children. London: WB Saunders, 1974.

12 Deal EC, McFadden ER, Ingram RH, Strauss RH, Jaeger JJ. Role of respiratory heat exchange in production of exercise-induced asthma. J Appl Physiol Respir Environ Exercise Physiol 1979;46:467-75.

${ }^{13}$ Silverman M, Anderson SD. Standardisation of exercise tests in asthmatic children. Arch Dis Child 1972;47:882-9.

${ }^{14}$ Stearns DR, McFadden ER, Breslin FJ, Ingram JR. Reanalysis of the refractory period in exertional asthma. J Appl Physiol: Respir Environ Exercise Physiol 1981;50:503-8.

15 Deal EC, Wasserman SI, Soter NA, Ingram RH, McFadden ER. Evaluation of role played by mediators of immediate hypersensitivity in exerciseinduced asthma, $J$ Clin Invest 1980;65:659-65.

${ }^{16}$ Barnes PG, Brown MG, Silverman M, Dollery CT. Circulating catecholamines in exercise and hyperventilation induced asthma. Thorax 1981;36:435-40.

${ }^{17}$ Lee TH, Nagy L, Nagakura T, Walport MJ, Kay AP. Identification and partial characterisation of an exercise-induced neutrophil chemotactic factor in bronchial asthma. J Clin Invest 1982;69:889-99.

${ }^{18}$ Ruffin RE, Alpers JH, Crockett AJ, Hamilton R. Repeated histamine inhalation tests in asthmatic patients. $J$ Allergy Clin Immunol 1981;67:285-9.

${ }^{19}$ Schoeffel RE, Anderson SD, Gillam I, Lindsay DA. Multiple exercise and histamine challenge in asthmatic patients. Thorax 1980;35:164-70. 